\title{
ANALYSIS OF METAL Pb AND Cu CONTENT IN SEAGRASS (Sargassum sp) IN BAYUR BAYS OF WEST SUMATERA PROVINCE
}

\author{
Yuliza Fitri $^{1 *}$, Yusni Ikhwan Siregar ${ }^{1}$, Bintal Amin ${ }^{1}$ \\ ${ }^{1}$ Department of Marine Science, Faculty of Fisheries and Marine Universitas Riau, Pekanbaru \\ *yulizafitri851@gmail.com
}

\begin{abstract}
Located in Teluk Bayur bay the port is of the five biggest and busiest ports in Indonesia. High sea transportation activities and anthropogenic activities may lead to heavy metal pollution. The purpose of this study was to determine the concentration of $\mathrm{Pb}$ and $\mathrm{Cu}$ metals, in seagrass (Sargassum sp.) and to analyze the feasibility of consuming Sargassum sp. The method used in this study is a survey method, by analyzing heavy metal at Laboratory Pekerjaan Umum of Riau Province. The water quality temperatures $30-31^{\circ} \mathrm{C}$, and salinity of 30-31 ppt, appeared curred velocity $0.06-0.08 \mathrm{~m} / \mathrm{sec}$, water transparency $100 \%$ with a depth of $\pm 1 \mathrm{~m}$ and $\mathrm{pH} 7 . \mathrm{Pb}$ concentrations the highest is $2.9367 \mu \mathrm{g} / \mathrm{g}$ at stations close to the port and the lowest is $2.2506 \mu \mathrm{g} / \mathrm{g}$ at stations close to tourist areas, and the concentration of $\mathrm{Cu}$ metal shows the highest $3.3850 \mu \mathrm{g} / \mathrm{g}$ at stations close to community settlements, and the lowest is $2.7772 \mu \mathrm{g} / \mathrm{g}$ near the port area of Teluk Bayur. Based on the PTWI value, Sargassum sp. those originating from the waters of Teluk Bayur, West Sumatra, are still safe for consumption. Based on the Anova $\mathrm{Pb}$ and $\mathrm{Cu}$ tests in Sargassum sp. do not different ( $\mathrm{p}>$ $0.05)$.
\end{abstract}

Keywords: Heavy Metal, $\mathrm{Pb}, \mathrm{Cu}$, Sargassum sp., Teluk Bayur Waters

\section{PENDAHULUAN}

Logam berat adalah unsur alami dari kerak bumi yang stabil dan tidak bisa rusak atau hancur sehingga cenderung menumpuk dalam tanah dan sedimen. Logam berat memiliki bobot jenis lebih besar dari 5 $\mathrm{gr} / \mathrm{cm}^{3}$, terletak di sudut kanan bawah sistem periodik, bernomor atom 22 sampai 92 dari perioda 4 sampai 7 , mempunyai afinitas yang tinggi terhadap unsur $\mathrm{S}$ menyebabkan logam berat mengikat unsur $S$ dalam enzim sehingga terbentuk ikatan gugus (-SH) dengan ion logam berat. Daya kerja yang dimiliki oleh enzim menjadi sangat berkurang atau sama sekali tidak dapat bekerja. Keadaan ini secara keseluruhan akan merusak sistem metabolisme [1].
Keberadaan logam berat di lingkungan berasal dari dua sumber. Pertama dari proses alamiah seperti pelapukan secara kimiawi dan kegiatan geokimiawi serta dari tumbuhan dan hewan yang membusuk. Kedua dari hasil aktivitas manusia maupun dari kegiatan industri [2]. Logam berat bersifat sulit di degradasi sehingga mudah terakumulasi dalam lingkungan perairan dan keberadaannya secara alami sulit terurai (dihilangkan), dapat terakumulasi dalam organisme termasuk kerang dan ikan yang dapat membahayakan kesehatan manusia yang mengkomsumsi organisme tersebut, mudah terakumulasi di sedimen sehingga konsentrasinya selalu lebih tinggi dari konsentrasi logam di dalam air, mudah tersuspensi karena pergerakan masa air 
yang akan melarutkan kembali logam yang di kandungnya ke dalam air sehingga sedimen menjadi sumber pencemar potensial dalam skala waktu tertentu [3-4].

Rumput laut atau seaweed adalah salah satu sumber daya hayati yang sangat melimpah di perairan Indonesia. Salah satu jenis rumput laut yang melimpah dan bernilai ekonomis adalah Sargassum sp., yang termasuk kedalam rumput laut coklat (Phaeophyceae) yang mengandung bahan alginat dan iodin. Sargassum sp. telah banyak dimanfaatkan sebagai bahan baku dalam bidang industri makanan, kosmetik, pakan, pupuk, tekstil, kertas dan sebagainya. [5] menyatakan bahwa rumput laut coklat memiliki komponen aktif berupa senyawa fenol, steroida, alkaloida dan triterpenoid yang berfungsi sebagai antibakteri, antivirus, antifouling, antikanker, biofertilizer dan anti jamur.

Rumput laut Sargassum sp. memiliki kemampuan biofilter yang dapat menyerap senyawa di perairan, termasuk logam timbal $(\mathrm{Pb})$ dan tembaga $(\mathrm{Cu})$. Menurut [6] rumput laut memiliki kemampuan dalam penyerapan logam berat dengan konsentrasi yang cukup tinggi. Oleh karena itu,
Sargassum sp. juga dimanfaatkan sebagai bioindikator pencemaran sekaligus biokontrol suatu perairan.

Teluk Bayur merupakan salah satu teluk yang terdapat di Kota Padang Sumatera Barat. Di Teluk Bayur terdapat pelabuhan yang merupakan salah satu dari lima pelabuhan terbesar dan tersibuk di Indonesia. Maka dari itu diduga banyak terdapat pencemaran yang terjadi di pelabuhan Teluk Bayur. Kemudian terdapat juga Pantai Nirwana yang merupakan salah satu pantai wisata dengan jaraknya sekitar $5,8 \mathrm{~km}$ dari Pelabuhan Teluk Bayur. Pada Pantai Nirwana banyak terdapat lamun, rumput laut, koral dan berbagai jenis ikan dan biota lainnya. Berkaitan dengan latar belakang di atas, maka dilakukan penelitian mengenai analisis kandungan logam $\mathrm{Pb}$ dan $\mathrm{Cu}$ pada rumput laut (Sargassum sp.) di perairan Teluk Bayur Provinsi Sumatera Barat

\section{METODE PENELITIAN Waktu dan Tempat}

Penelitian ini dilaksanakan di perairan Teluk Bayur Kota Padang Provinsi Sumatera Barat (Gambar 1).

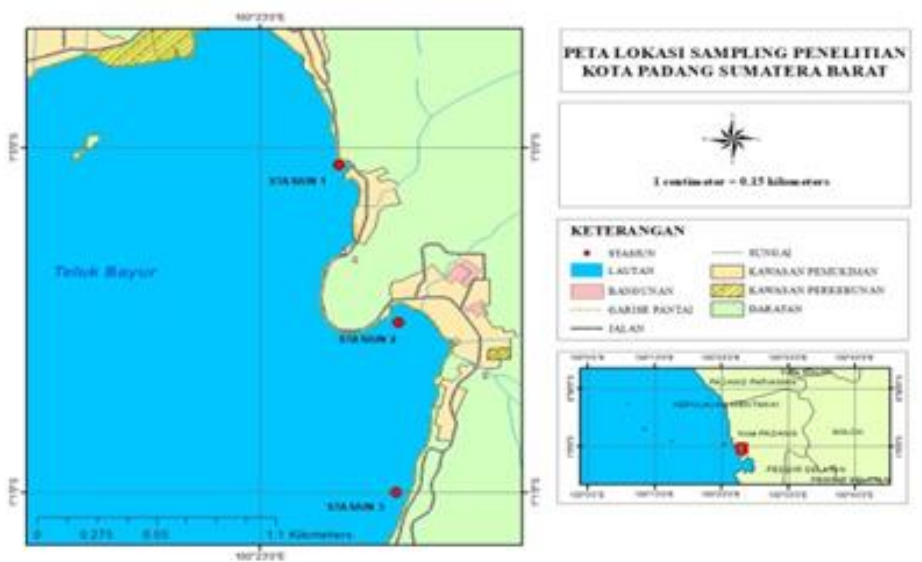

Gambar 1. Peta Lokasi Penelitian

\section{Metode Penelitian}

Metode yang digunakan pada penelitian ini adalah metode survey, Sampel Sargassum sp. yang diperoleh dianalisis konsentrasi logam beratnya di laboratorium Dinas Pekerjaan Umum Provinsi Riau. Seluruh data kemudian dianalisis secara statistik dan dibahas secara deskriptif dengan berbagai literatur yang relevan. 


\section{Prosedur Penelitian}

Penentuan Lokasi Sampling

Lokasi pengambilan sampel rumput laut Sargassum sp. ditentukan secara purposive sampling yang dibagi atas 3 stasiun pada kawasan Teluk Bayur Sumatera Barat. Stasiun 1 di sekitar Pelabuhan Teluk Bayur, stasiun 2 berada pada kawasan pesisir padat penduduk yaitu tepatnya di Desa Sungai Beremas, dan stasiun 3 di sekitar Pantai Nirwana yang merupakan kawasan wisata.

\section{Pengukuran Kualitas Perairan}

Pengukuran parameter kualitas perairan seperti suhu, $\mathrm{pH}$, salinitas dan kecerahan dilakukan pada saat pengambilan sampel di setiap stasiun yang bertujuan untuk menggambarkan kondisi perairan pada saat penelitian.

\section{Pengambilan dan Penanganan Sampel}

Sampel Sargassum sp. diambil secara langsung dengan menggunakan tangan di setiap lokasi sampling. Sampel Sargassum sp. diambil sebanyak 1000 gr dari semua stasiun yang dianggap telah mewakili keseluruhan perairan Teluk Bayur. Sampel yang diambil kemudian dibersihkan dan dimasukkan ke dalam kantong plastik yang diberi label berdasarkan stasiun. Kemudian sampel dimasukkan ke dalam ice box, dan dibawa ke laboratorium untuk dilakukan identifikasi dan disimpan dalam lemari pendingin hingga analisis dilakukan.

\section{Analisis Logam $\mathrm{Pb}$ dan $\mathrm{Cu}$ pada Sargassum sp.}

Analisis logam pada Sargassum sp terdapat beberapa langkah, diantaranya adalah sebagai berikut:

Penghancuran (Destruksi). Sampel Sargassum sp. dikeringkan dengan oven pada suhu $80^{\circ} \mathrm{C}$. Semua peralatan yang digunakan direndam dengan laruran $\mathrm{HCl}$ 5\% selama 24 jam, kemudian dibilas dengan air suling berkali-kali, hal ini dilakukan untuk menghindari kemungkinan terjadinya kontaminasi. Sampel diambil 1 gr kemudian dilarutkan ke dalam $10 \mathrm{ml}$ asam nitrat pekar $\left(\mathrm{HNO}_{3}\right)$ dan diletakkan pada alat pemanas (hot plate), tahap pertama pada suhu rendah $\left(40^{\circ} \mathrm{C}\right)$ selama 1 jam dan kemudian dilanjutkan pada suhu yang lebih tinggi yaitu $140^{\circ} \mathrm{C}$ selama 3 jam, setelah itu larutan didinginkan.

Penyaringan. Larutan sampel yang telah dingin kemudian ditambahkan aquades sehingga volumenya menjadi 50 $\mathrm{ml}$ lalu disaring kedalam botol sampel. Penyaringan dilakukan dengan kertas whattman berukuran $0,45 \mu \mathrm{m}$.

Pengujian larutan blanko dan pembuatan larutan standar. Pengujian larutan blanko dilakukan untuk mendapatkan hasil pengukuran yang benarbenar berasal dari sampel yang dianalisis, karena pada bahan-bahan pereaksi yang digunakan pada saat proses destruksi dan penyaringan kemungkinan terdapat kandungan logam berat walaupun dalam jumlah yang sedikit, larutan yang digunakan adalah $\mathrm{HNO}_{3}$ dimana larutan $\mathrm{HNO}_{3}$ juga diberikan perlakuan yang sama dengan sampel tetapi tidak ditambahkan sampel dan kemudian diukur dengan AAS.

Larutan standar diperoleh dari larutan $\mathrm{Pb}$ dan $\mathrm{Cu}$ dengan konsentrasi awal 1000 ppm. Larutan ini kemudian diencerkan menjadi konsentrasi 0,05 ppm, 0,1 ppm, 0,2 ppm dan 0,5 ppm. Kurva yang diperoleh dari kadar nyata dengan nilai absorbansinya dari larutan standar yang ditunjukkan oleh AAS membentuk garis linier.

\section{Perhitungan konsentrasi logam} berat. Konsentrasi logam berat pada sampel dihitung menggunakan rumus [7] yaitu sebagai berikut:

$$
\mathrm{K}=(\mathrm{D} \times \mathrm{B}) / \mathrm{A}
$$

Keterangan:

$\begin{aligned} \mathrm{K}= & \text { Konsentrasi yang } \\ & \text { dari sampel }(\mu / \mathrm{g}) \\ \mathrm{D}= & \begin{array}{l}\text { Kandungan yang dihitung } \\ \text { berdasarkan nilai absorbansi } \\ \\ (\mu / \mathrm{ml})\end{array}\end{aligned}$


$\mathrm{B}=$ Volume Sampel $(\mathrm{ml})$

$\mathrm{A} \quad=$ Berat Sampel $(\mathrm{g})$

\section{Perhitungan Status Pencemaran Logam Berat}

Untuk mengetahui status pencemaran dan juga dampak negatif dari logam berat yang dianalisis pada masing-masing stasiun dilakukan menurut [8] yaitu dengan menggunakan rumus Metal Polution Index (MPI)

$$
\text { MPI }=n \sqrt{ } \mathbf{C} 1 \times C 2 \times C 3 \ldots . . C n
$$

Keterangan :

MPI = Metal Pollution Index

$\mathrm{n} \quad=$ Jumlah logam

$\mathrm{Cn}=$ Kandungan logam pada sampel

\section{Batasan Aman Konsumsi}

Menurut [9] perhitungan batas aman konsumsi dihitung dengan persamaan sebagai berikut:

\section{PTWI = Baku mutu logam berat $\mathrm{x}$ Berat badan x 1000}

Keterangan:

$\begin{array}{ll}\text { PTWI } & \begin{array}{l}\text { Provisional Tolerable Weekly } \\ \text { Intake }(\mu \mathrm{g} / \mathrm{Kg} / \text { minggu })\end{array} \\ \begin{array}{ll}\text { Baku mutu }= & \text { Nilai baku mutu setiap logam } \\ \text { logam } & \text { yang diperbolehkan masuk } \\ & \mathrm{ke} \mathrm{dalam} \mathrm{tubuh} \mathrm{manusia} \\ & (\mu / \mathrm{Kg} / \text { minggu })\end{array} \\ \text { Berat badan }= & 70 \mathrm{~kg} \text { (Standar Internasional }) \\ 1000 & =\text { Konversi mg ke } \mu \mathrm{g}\end{array}$

Selanjutnya untuk mengetahui batas aman konsumsi alga coklat Sargassum sp. dilakukan dengan perhitungan sebagai berikut:

$$
\begin{aligned}
& \text { Batas aman konsumsi }(\mathrm{Kg} / \mathrm{minggu})= \\
& \text { PTWI : K : } \mathbf{1 0 0 0} \\
& \text { Keterangan : }
\end{aligned}
$$

\section{Analisis Data}

Data konsentrasi logam berat $\mathrm{Pb}$ dan $\mathrm{Cu}$ yang diperoleh dianalisis secara statistik dan dibahas secara deskriptif dengan mengacu pada literatur yang relevan dan membandingkan dengan penelitian yang sama pada lokasi yang berbeda.

\section{HASIL DAN PEMBAHASAN \\ Keadaan Umum Lokasi Penelitian}

Kota Padang adalah kota terbesar di pantai barat Pulau Sumatra merupakan ibu kota provinsi Sumatra Barat, Indonesia. Kota ini merupakan pintu gerbang barat Indonesia dari Samudra Hindia. Wilayah administratifnya memiliki luas $694,96 \mathrm{~km}^{2}$ dengan kondisi geografi berbatasan laut dan dikelilingi perbukitan yang mencapai ketinggian $1.853 \mathrm{mdpl}$ dan memiliki jumlah penduduk sebanyak 927.168 jiwa.

Teluk Bayur merupakan salah satu teluk yang terdapat di Kota Padang Sumatera Barat. Di Teluk Bayur terdapat pelabuhan yang merupakan salah satu dari lima pelabuhan terbesar dan tersibuk di Indonesia. Kemudian terdapat juga Pantai Nirwana yang merupakan salah satu pantai wisata yang berada di Teluk Bayur dengan jaraknya sekitar $5,8 \mathrm{~km}$ dari pelabuhan Teluk Bayur. Pada Pantai Nirwana banyak terdapat makhluk hidup mulai dari lamun, rumput laut, koral dan berbagai jenis ikan dan biota lainnya.

\section{Parameter Kualitas Perairan}

Tabel 1 dapat dilihat bahwa perairan Teluk Bayur memiliki suhu berkisar 30$31^{\circ} \mathrm{C}$, dan salinitas 30-31 ppt, kecepatan arus berkisar 0,06-0,08 m/detik, kecerahan $100 \%$ dengan kedalaman $\pm 1 \mathrm{~m}$ dan $\mathrm{pH} 7$, pengukuran kualitas perairan ini dilakukan pada saat surut.

Parameter kualitas perairan sangat mempengaruhi keberadaan logam berat di dalam air, sedimen, dan terakumulasi dalam tubuh biota laut. [1] menyatakan kenaikan suhu air laut akan mempengaruhi adopsi senyawa logam berat pada partikulat 
dan mengakibatkan logam berat melarut di air laut, sementara saat suhu air laut lebih dingin akan meningkatkan abrorbsi logam berat dalam air sangat di kontrol oleh $\mathrm{pH}$ air, apabila terjadi kenaikan $\mathrm{pH}$ air maka dapat menurunkan kelarutan logam didalam air, hal ini terjadi karena kenaikan $\mathrm{pH}$ mengubah kestabilan dari bentuk karbonat menjadi hidroksida yang membentuk ikatan partikel pada badan air, sehingga akan mengendap bersama lumpur.

Tabel 1. Hasil Pengukuran Parameter Kualitas Perairan

\begin{tabular}{|c|c|c|c|c|c|c|}
\hline \multirow[b]{2}{*}{ Stasiun } & \multicolumn{6}{|c|}{ Parameter Kualitas Perairan } \\
\hline & Titik koordinat & Suhu $\left({ }^{\circ} \mathrm{C}\right)$ & $\begin{array}{c}\text { Salinitas } \\
\text { (ppt) }\end{array}$ & $\begin{array}{c}\text { Kecepatan } \\
\text { (m/detik) }\end{array}$ & $\begin{array}{c}\text { Kecerahan } \\
(\%)\end{array}$ & pH \\
\hline 1 & $\begin{array}{l}1^{\circ} 00^{\prime} 03^{\prime \prime} \mathrm{S} \\
100^{\circ} 23^{\prime} 12^{\prime \prime} \mathrm{E}\end{array}$ & 30 & 31 & 0,08 & 100 & 7 \\
\hline 2 & $\begin{array}{l}1^{\circ} 00^{\prime} 30^{\prime \prime} \mathrm{S} \\
100^{\circ} 23 \text { '20"E }\end{array}$ & 30 & 30 & 0,06 & 100 & 7 \\
\hline 3 & $\begin{array}{l}1^{\circ} 00^{\prime} 59^{\prime \prime} \mathrm{S} \\
100^{\circ} 23,20^{\prime \prime} \mathrm{E}\end{array}$ & 31 & 31 & 0,07 & 100 & 7 \\
\hline Rata-rata & & 30,33 & 30,66 & 0,07 & 100 & 7 \\
\hline
\end{tabular}

Menurut [10] suhu yang baik untuk pertumbuhan rumput laut berkisar 24-31 ${ }^{\circ} \mathrm{C}$ dan salinitas yang baik berkisar antara 28-30 ppt dengan nilai optimum adalah 33 ppt. [11] menyatakan rumput laut memerlukan cahaya sebagai sumber energi guna pembentukan bahan organik yang diperlukan bagi pertumbuhan dan perkembangannya yang normal.

Arus dapat terjadi karena pasang dan angin. Arus terlalu banyak menyebabkan kerusakan pada tanaman dibandingkan dengan ombak, kisaran kecepatan arus yang cukup untuk pertumbuhan rumput laut antara 20-30 cm/detik [12]. [13] menyatakan rumput laut memperoleh makanan melalui aliran air yang melewatinya. Gerakan air yang cukup akan menghindari terkumpulnya kotoran pada thallus dan mencegah adanya fluktuasi yang besar terhadap salinitas maupun suhu air.

\section{Konsentrasi Logam $\mathrm{Pb}$ dan $\mathrm{Cu}$ pada Sargassum sp.}

Konsentrasi logam $\mathrm{Pb}$ n nilai rata-rata 2,5196 $\mu \mathrm{g} / \mathrm{g}$. Konsentrasi logam Pb paling tinggi terdapat di stasiun 1 dan terendah terdapat di stasiun 3. Konsentrasi logam $\mathrm{Cu}$ berkisar antara 2,7772-3,2911 $\mu \mathrm{g} / \mathrm{g}$ dengan rata-rata $3,1511 \mu \mathrm{g} / \mathrm{g}$. Konsentrasi logam $\mathrm{Cu}$ paling tinggi terdapat di stasiun 2 dan terendah terdapat di stasiun 1 (Tabel 2).

Tabel 2. Konsentrasi (Rata-rata \pm Standar Deviasi) Logam $\mathrm{Pb}$ dan $\mathrm{Cu}$ pada Sargassum $\mathrm{sp}$

\begin{tabular}{ccc}
\hline \multirow{2}{*}{ Stasiun } & \multicolumn{2}{c}{ Konsentrasi Logam Berat $\boldsymbol{\mu g} / \mathbf{g}$} \\
\cline { 2 - 3 } & $\mathbf{P b}$ & $\mathbf{C u}$ \\
\hline 1 & $2,9367 \pm 0,2258$ & $2,7772 \pm 0,3505$ \\
2 & $2,3717 \pm 0,3833$ & $3,3850 \pm 0,6630$ \\
3 & $2,2506 \pm 0,5307$ & $3,2911 \pm 0,2647$ \\
\hline Rata-rata & $2,5196 \pm 0,3662$ & $3,1511 \pm 0,2096$ \\
\hline
\end{tabular}

Hasil pengukuran konsentrasi logam $\mathrm{Pb}$ dan $\mathrm{Cu}$ pada Sargassum sp. keseluruhan stasiun di perairan Teluk Bayur Provinsi Sumatera Barat dapat dilihat pada Tabel 2.
Konsentrasi logam $\mathrm{Pb}$ dengan rata-rata $2,5196 \mu \mathrm{g} / \mathrm{g}$. Stasiun 1 merupakan stasiun yang memiliki konsentrasi logam $\mathrm{Pb}$ tertinggi yaitu $2,9367 \mu \mathrm{g} / \mathrm{g}$ dan yang 
terendah pada stasiun 3 yaitu 2,2506 $\mu \mathrm{g} / \mathrm{g}$. Hal ini disebabkan karena stasiun 1 yang merupakan daerah yang terdekat dari aktivitas pelabuhan dan lewatnya kapalkapal besar. Stasiun 1 dan 2 memiliki suhu $30^{\circ} \mathrm{C}$ yang tergolong rendah dari stasiun 3 . Biasanya suhu dipengaruhi oleh musim, cuaca, kedalaman, dan kecerahan. kenaikan suhu air laut akan mengurangi adsorpsi senyawa logam berat pada partikulat. saat suhu air laut naik, senyawa logam berat akan melarut di air laut karena penurunan laju adsorpsi kedalam partikulat [1].

Konsentrasi logam $\mathrm{Cu}$ dengan ratarata $3,1511 \mu \mathrm{g} / \mathrm{g}$. Konsentrasi tertinggi terdapat pada Stasiun 2 yaitu 3,3850 $\mu \mathrm{g} / \mathrm{g}$ dan yang terendah terdapat pada Stasiun 1 yaitu $2,7772 \mu \mathrm{g} / \mathrm{g}$. Hal ini diduga karena pada stasiun 1 merupakan daerah Pelabuhan selain itu dari hasil penelitian menunjukkan konsentrasi logam $\mathrm{Cu}$ lebih tinggi jika dibandingkan dengan logam $\mathrm{Pb}$
Seperti yang dikatakan oleh [14] bahwa aktifitas manusia dapat meningkatkan kosentrasi logam menjadi lebih tinggi. Pertambangan dan pengolahan biji, limbah domestik, limbah air, limpasan air hujan dan pembuangan limbah industri merupakan sumber utama pencemaran logam berat.

\section{Status Pencemaran Perairan Teluk Bayur Provinsi Sumatera Barat}

Hasil perhitungan menunjukkan MPI

di Perairan Teluk Bayur Kota Padang Provinsi Sumatera Barat adalah 2,8177. Penentuan status pencemaran konsentrasi logam berat di perairan Teluk Bayur Provinsi Sumatera Barat dapat dilihat dengan metal pollution index (MPI) berdasarkan rumus [8]. Untuk melihat perbandingan nilai MPI perairan Teluk Bayur kota Padang Provinsi Sumatera Barat dapat dilihat pada Tabel 3.

Tabel 3. Perbandingan nilai Mpi perairan Teluk Bayur kota Padang provinsi Sumatera Barat dengan penelitian di daerah lain

\begin{tabular}{lccc}
\hline \multicolumn{1}{c}{ Perairan } & Spesies & MPI & Penelitian \\
\hline Pantai Pandawa & Gracilaria sp. & 2084,22 & {$[15]$} \\
Pesisir Teluk Lampung & Sargassum sp. & 164,76 & {$[16]$} \\
Panipahan & Anadara granosa & 5,03 & {$[17]$} \\
\hline
\end{tabular}

Nilai MPI perairan Pantai Pandawa [15] dan Pesisir Teluk Lampung [16] menunjukkan tingkat pencemaran diperairan tersebut lebih tinggi dari perairan Panipahan. Batas Aman Konsumsi Sargaassum sp. di Perairan Teluk Bayur Provinsi Sumatera Barat Pada Tabel 4 terlihat bahwa orang dewasa dengan berat badan $70 \mathrm{~kg}$ memiliki batas aman konsumsi Sargassum sp. yang berasal dari perairan Teluk Bayur Kota Padang Provinsi Sumatera Barat adalah 166,67 kg/minggu untuk logam $\mathrm{Pb}$ dan 310,13 kg/minggu untuk logam $\mathrm{Cu}$.

Tabel 4. Batas Aman Konsumsi Sargassum sp. yang berasal dari Perairan Teluk Bayur Provinsi Sumatera Barat

\begin{tabular}{cccc}
\hline Logam & $\begin{array}{c}\text { Nilai PTWI } \\
(\boldsymbol{\mu g} / \mathbf{k g})\end{array}$ & $\begin{array}{c}\text { Konversi Sampel } \\
\text { Kering }: \text { Basah }(\mathbf{1 : 4})\end{array}$ & $\begin{array}{c}\text { Batas Aman Konsumsi } \\
(\mathbf{k g} / \mathbf{m i n g g u})\end{array}$ \\
\hline $\mathrm{Pb}$ & 105.000 & 0,63 & 166,67 \\
$\mathrm{Cu}$ & 245.000 & 0,79 & 310,13 \\
\hline
\end{tabular}

Pada masyarakat Aceh Sargassum sp. dimanfaatkan sebagai teh herbal dan juga dimanfaatkan sebagai pewarna makanan seperti mie aceh dan pada masyarakat Teluk Awur Kota Jepara Sargassum sp. dimanfaatkan sebagai 
keripik, Pengembangan teknologi aplikasi alga cokelat Sargassum sp. tidak hanya pada bidang pangan seperti alginat, makanan ternak serta pupuk, akan tetapi antioksidan yang terdapat pada alga cokelat Sargassum sp. juga mampu menghambat kerusakan yang ditimbulkan oleh radikal bebas pada produk seperti minyak ikan [1819].

Batas aman atau kelayakan konsumsi Sargassum sp. di perairan Teluk Bayur Provinsi Sumatera Barat dari nilai rata-rata konsentrasi masing-masing logam. sehingga diperoleh nilai PTWI yang telah ditetapkan FAO/WHO akan tercapai apabila masyarakat dengan berat badan 70 $\mathrm{kg}$ mengkonsumsi Sargassum sp. yang berasal dari perairan Teluk Bayur Provinsi Sumatera Barat tidak lebih dari 166,67 $\mathrm{kg} /$ minggu untuk logam $\mathrm{Pb}$ dan 310,13 $\mathrm{kg} /$ minggu untuk logam $\mathrm{Cu}$. Besarnya nilai PTWI Sargassum sp. yang diambil dari perairan Teluk Bayur Kota Padang Provinsi Sumatera Barat dapat menggambarkan bahwa Sargassum sp. yang ada di perairan tersebut masih layak konsumsi, selama tidak melampaui batas yang telah ditentukan.

\section{KESIMPULAN DAN SARAN Kesimpulan}

Konsentrasi logam $\mathrm{Pb}$ pada Sargassum sp. lebih kecil dari pada konsentrasi logam $\mathrm{Cu}$. Konsentrasi logam $\mathrm{Pb}$ pada Sargassum sp. berkisar 2,2506$2,9367 \mu \mathrm{g} / \mathrm{g}$. Konsentrasi logam $\mathrm{Cu}$ pada Sargassum sp. berkisar 2,7772-3,3850 $\mu \mathrm{g} / \mathrm{g}$. Nilai PTWI logam $\mathrm{Pb}$ dan $\mathrm{Cu}$ pada Sargassum sp. yang berasal dari perairan Teluk Bayur Sumatera Barat masih layak dikonsumsi. Hasil analisis statistik (uji Anova) kandungan logam $\mathrm{Pb}$ dan $\mathrm{Cu}$ pada rumput laut Sargassum sp. di Teluk Bayur Provinsi Sumatera Barat tidak berbeda nyata antar stasiun $(\mathrm{p}>0,05)$.

\section{Saran}

Adapun saran dari penelitian ini adalah perlu dilakukan penelitian lanjut tentang konsentrasi logam berat pada air, sedimen dan biota lain sebagai indikator pencemar. Di karenakan banyaknya Sargassum sp. di perairan Teluk Bayur ada baiknya penelitian selanjutnya tentang pemanfaatan Sargassum sp.

\section{DAFTAR PUSTAKA}

1. Pallar, S. (2004). Toksikologi Logam Berat dan Pencemaran Lingkungan, Edisi ke-2. Rineka Cipta. Jakarta.

2. Connel dan Miller. (1995). Kimia dan Etoksikologi Pencemaran. diterjemahkan oleh Koestoer, S., Indonesia University Press, Jakarta. $419 \mathrm{hlm}$.

3. Sumanti, S., I. Nurrachmi, dan Y.I. Siregar. (2019). Analysis of Pb, Cu and $\mathrm{Zn}$ Metal Contents in Red Chut-Chut Snail (Cerithidea obtusa) and Sediment in Mendol Island Kuala Kampar of riau Province. Asian Journal of Aquatic Sciences, 2(2): 153-161

4. Harlyan, L.I dan S.H.J. Sari. (2015). Konsentrasi Logam Berat Pb, Cu, dan Zn pada Air dan Sedimen Permukaan Ekosistem Mangrove di Muara Sungai Porong Sidoarjo, Jawa Timur. Jurnal Perikanan dan Kelautan, 20(1): 52-61

5. Azizah, N.S.K., E.N. Dewi dan A.S. Fahmi. (2017). Potensi Ekstrak Kasar Alga Cokelat (Sargassum sp) dalam Menghambat Oksidasi pada Udang Vannamei (Litopennaeus vannamei) Segar Selama Penyimpanan Dingin. Jurnal Saintek Perikanan, 13(1): 45-51.

6. Ihsan, Y.N., A. Aprodita, I. Rustikawati dan T.D.K. Pribadi. (2015). Kemampuan Gracilaria sp. sebagai Agen Bioremediasi dalam Menyerap Logam Berat Pb. Jurnal Kelautan, 8(1):10-18. 
7. Siregar, Y.I. (2017). Accumulation of $\mathrm{Pb}, \mathrm{Cu}$ and $\mathrm{Zn}$ in Organ System of Parang Fish (Chirocentrus dorab) and Biang Fish (Setipinna paxtoni) from Meranti Islands, Sumatera Indonesia. International Journal of Applied Environmental Sciences, 12(8): $1575-1584$

8. Usero, J., J. Morillo dan I. Gracia. (2005). Heavy Metal Concentration in Mollusks From the Atlantic Coast of Southern Spain. Chemosphere, 59:1175-1181.

9. FAO/WHO. (2004). Summary of Evaluation Performed by The Join. FAO. WHO Expert Commite on Food Additivites (JECFA 1956-2003). ILSI Press International Life Sciences Institute

10. Anggadiredja, J.T., A. Zatnika, H. Purwanto, dan S. Istini. (2006). Rumput Laut. Penerbit Swadaya. Jakarta.

11. Agustina, L. (2004). Dasar Nutrisi Tanaman. Jakarta: PT Rineka Cipta

12. Sulistijo. (2002). Penelitian Budidaya Rumput Laut (Algae makro/Seaweed) di indonesia. Pusat Penelitian Oseanografi Lembaga Ilmu Pengetahuan Indonesia. Jakarta

13. Ditjenkanbud. (2004). Profil Rumput Laut Indonesia. Dinas Kelautan dan Perikanan Republik Indonesia, Ditjenkanbud. Jakarta.

14. Saavedra, Y., A. Gonzalez, P. Fernandez, dan J. Blanco. (2004). Interspecific Variation of Metal Concentrations in Three Bivalve Mollusks from Galicia. Arc. Environ. Contaminat. Toxicolog, 47:341-351

15. Siaka, I. M,. N.G.A.M.D. Suastuti dan I.P.B. Mahendra. (2016). Distribusi Logam Berat $\mathrm{Pb}$ dan $\mathrm{Cu}$ pada Air Laut, Sedimen, dan Rumput Laut di Perairan Pantai Pandawa. Jurnal Kimia, 10 (2): 190-196

16. Manalu, F.E. (2017). Kajian Kandungan Logam Berat Timbal (Pb), Kadmium (Cd), Kromium $(\mathrm{Cr})$, Tembaga $(\mathrm{Cu})$, dan Mangan (Mn) pada Rumput laut (Sargassum $\mathrm{sp}$ ) di Pesisir Teluk Lampung Secara Spektrofotometri Serapan atom. Skripsi. Fakultas Matemetika dan Ilmu Pengetahuan Alam Universitas Lampung. Bandar Lampung

17. Arnes., Rifardi, dan B. Amin. (2021). Lead and Copper Concentration in Sediment and Blood Cockle (Anadara granosa) in the Coastal Waters of Panipahan, Rokan Hilir, Riau Province. Journal of Coastal and Ocean Sciences, 2(1): 28-35

18. Patra, J.K., S.K. Rath, dan K. Jena. (2008). Evaluation of Antioxidant and Antimicrobial Activity of Seaweed (Sargassum sp.) Extract: A Study on Inhibition of Glutathione-S-Transferase Activity. Turkish Journal of Biology. 32: 119-125.

19. Winberg, P., D. Ghosh dan L. Tapsell. (2009). Seaweed Culture in Integrated (MultiTrophic Aquaculture). Rural Industries Research and Development Corporation. Australia. 